\title{
Non-canonical NF-kB signaling in rheumatoid arthritis: Dr Jekyll and Mr Hyde?
}

Ae R Noort ${ }^{1,2}$, Paul P Tak ${ }^{1,3,4}$ and Sander W Tas ${ }^{1,2^{*}}$

\begin{tabular}{|l|}
\hline Abstract \\
The nuclear factor-kB (NF-kB) family of transcription \\
factors is essential for the expression of pro-inflammatory \\
cytokines, but can also induce regulatory pathways. \\
NF-kB can be activated via two distinct pathways: the \\
classical or canonical pathway, and the alternative or \\
non-canonical pathway. It is well established that the \\
canonical NF-kB pathway is essential both in acute \\
inflammatory responses and in chronic inflammatory \\
diseases, including rheumatoid arthritis (RA). Although \\
less extensively studied, the non-canonical NF-kB \\
pathway is not only central in lymphoid organ \\
development and adaptive immune responses, but \\
is also thought to play an important role in the \\
pathogenesis of RA. Importantly, this pathway appears \\
to have cell type-specific functions and, since many \\
different cell types are involved in the pathogenesis of \\
RA, it is difficult to predict the net overall contribution \\
of the non-canonical NF-kB pathway to synovial \\
inflammation. In this review, we describe the current \\
understanding of non-canonical NF-kB signaling in \\
various important cell types in the context of RA and \\
consider the relevance to the pathogenesis of the \\
disease. In addition, we discuss current drugs targeting \\
this pathway, as well as future therapeutic prospects.
\end{tabular}

\section{Introduction}

\section{Rheumatoid arthritis}

Rheumatoid arthritis (RA) is a disabling chronic inflammatory autoimmune disease affecting the synovial joints. In the early phase of the disease, the synovial tissue is infiltrated by immune cells and increases in thickness, which causes pain, stiffness and swelling of the joint. The

\footnotetext{
*Correspondence: S.W.Tas@amc.uva.nl

'Department of Clinical Immunology \& Rheumatology, Academic Medical Center/University of Amsterdam, 1105AZ Amsterdam, The Netherlands ${ }^{2}$ Department of Experimental Immunology, Academic Medical Center/ University of Amsterdam, 1105 AZ Amsterdam, The Netherlands Full list of author information is available at the end of the article
}

synovial cell infiltrate contains various lymphocytes, plasma cells, macrophages, and other cells. These cells contribute to the inflammatory process via the production of matrix metalloproteinases (MMPs), cytokines and chemokines, followed by the influx and activation of more immune cells into the synovial tissue. From the earliest stage of the disease, neoangiogenesis can be observed, which contributes to chronicity. Eventually, the loss of articular cartilage, along with damage to the joint capsule and peri-articular structures, causes deformities (reviewed in [1]).

In RA synovial tissue many signal transduction pathways are activated [2]. One of the most important signaling pathways involved in the pathogenesis of RA is the nuclear factor- $\mathrm{kB}(\mathrm{NF}-\mathrm{\kappa} \mathrm{B})$ pathway (reviewed in [3]).

\section{Nuclear factor-кB}

NF- $k B$ is expressed ubiquitously in the cytoplasm of almost all cell types. Many diseases, including cancer, and inflammatory and autoimmune diseases, are associated with dysregulation of NF- $\mathrm{kB}$ (reviewed in [4]). NF- $\mathrm{kB}$ can be activated via two distinct pathways, the classical or canonical $\mathrm{NF}-\mathrm{KB}$ pathway, and the alternative or non-canonical NF-kB pathway.

\section{The canonical NF-KB pathway}

The most extensively studied NF- $\mathrm{kB}$ activation pathway is the canonical pathway (Figure 1), which can be activated by stimulation of a variety of cell membrane receptors, including tumor necrosis factor (TNF) receptor, interleukin (IL)-1 receptor, and Toll-like receptors, in response to pro-inflammatory stimuli like lipopolysaccharide, IL-1 and TNF, as well as via triggering of the T-cell receptor or B-cell receptor. In this pathway, inhibitor of $\kappa B$ kinase (IKK) $\beta$ is required for NF- $\kappa B$ activation, whereas IKK $\alpha$ is redundant [4]. The canonical NF- $k B$ pathway is essential both in acute inflammatory responses and in chronic inflammatory diseases such as RA and inflammatory bowel disease. Moreover, this pathway is important in cell proliferation and survival, demonstrated by constitutively active NF- $\mathrm{kB}$ signaling in many tumor tissues [5]. In 


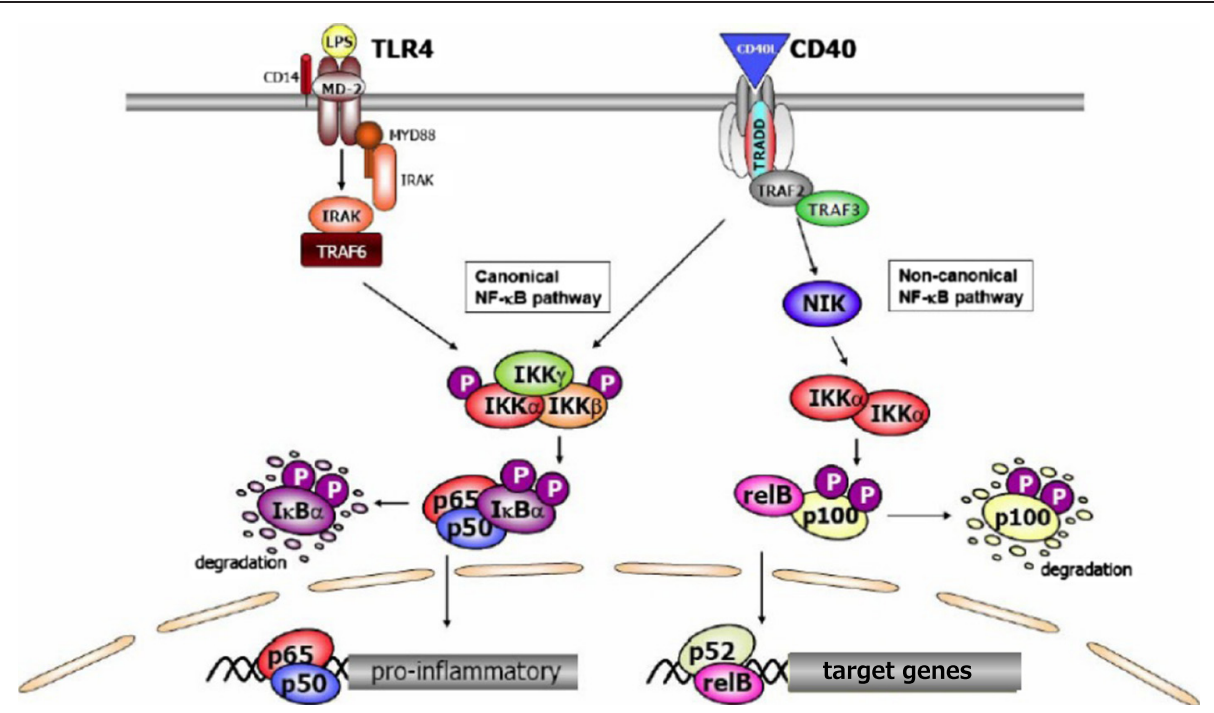

Figure 1 Overview of nuclear factor-KB activation pathways. Schematic representation of the canonical and non-canonical nuclear factor (NF)-KB pathways. The canonical NF-KB pathway can be activated by a variety of different stimuli, like tumor necrosis factor-a and lipopolysaccharide (LPS). Activation of the canonical pathway via Toll-like receptor or cytokine receptor signaling depends on the inhibitor of $\mathrm{KB}$ kinase (IKK) complex, which is composed of the kinases IKKa and IKKß, and the regulatory subunit IKKY (NEMO). Activated IKK phosphorylates the inhibitory subunit $\mathrm{I} \mathrm{KBa}$ to induce its degradation, allowing NF-KB dimers (p50-p65) to translocate to the nucleus and bind to DNA to induce NF-KB target gene transcription. The non-canonical pathway (right) is activated by specific stimuli like B cell activating factor, lymphotoxin $\beta$, LIGHT and CD40L. NF-KB inducing kinase (NIK) is stabilized and activates and recruits IKKa into the p100 complex to phosphorylate p100, leading to p100 ubiquitination. Processing of p100 generates the p52/RelB NF-KB complex, which is able to translocate to the nucleus and induce gene expression.

RA IKK $\beta$ is a key regulator of synovial inflammation [6] and the importance of the canonical NF-kB pathway in arthritis is underlined by the beneficial effects of specific IKK $\beta$ inhibition in preclinical models of arthritis [6,7] and the common and successful use of anti-TNF therapy in $\mathrm{RA}$, one of the main target genes of the canonical NF- $\mathrm{kB}$ pathway. This is outside the scope of the current review, however, but is discussed in more detail in previous reviews $[2,3]$. Here we focus on the alternative or noncanonical NF-kB pathway.

\section{The non-canonical NF- $\kappa B$ pathway}

In the past decade, a second, alternative NF- $\mathrm{kB}$ activation pathway was identified, the so-called non-canonical NF-kB pathway (Figure 1). This pathway can be triggered by the activation of members of the TNF-receptor superfamily including the lymphotoxin $\beta$ (LT $\beta$ ) receptor (LT $\beta R$ ), CD40, B cell activating factor (BAFF) belonging to the TNF family receptor, and receptor activator of NF-KB (RANK). Of note, these receptors not only trigger the non-canonical NF- $\mathrm{KB}$ pathway, but simultaneously also the canonical pathway. The non-canonical NF- $k B$ pathway is strictly dependent on IKK $\alpha$ homodimers and unlike the canonical pathway does not involve IKK $\beta$ or IKK $\gamma$ [8]. In the steady state, NF-KB inducing kinase (NIK), the most important kinase of the non-canonical pathway, is continuously degraded. TRAF3 mediates recruitment of NIK to TRAF2, which leads to ubiquitination of NIK. Consequently, endogenous levels of NIK are very low and the NF- $\mathrm{kB}$ complex is retained in the cytoplasm and kept inactive. Upon signal-induced activation of the non-canonical NF-kB pathway, TRAF2 induces proteolysis of TRAF3. Degradation of TRAF3 prevents targeting of newly synthesized NIK, resulting in accumulation of NIK. Subsequently, NIK induces processing of p100 by IKK $\alpha$ homodimers, resulting in partial degradation into p52. Next, mainly p52-RelB heterodimers translocate to the nucleus, leading to target gene transcription. Whereas canonical NF- $\kappa B$ activation is rapid and independent of protein synthesis, non-canonical NF- $\kappa \mathrm{B}$ activation requires NIK synthesis and accumulation. Consequently, the kinetics of this pathway are considerable slower (reviewed in $[4,8]$ ).

Of note, ligands of the TNF-receptor superfamily simultaneously also activate the canonical pathway and regulated cross-talk between both pathways exists at different levels. IKK $\alpha$ has, for instance, been described to also have nuclear functions and serves as a regulator of canonical NF-kB-dependent gene expression through control of promoter-associated histone phosphorylation after cytokine exposure $[9,10]$. In macrophages, however, IKK $\alpha$ also terminates canonical NF- $\kappa B$-dependent transcription of target genes by accelerating both the turnover of the NF- $\mathrm{kB}$ subunits RelA and c-Rel and their removal from pro-inflammatory gene promoters [11]. Reciprocally, canonical NF- $\mathrm{B}$ activity suppresses basal non-canonical 
NF- $\mathrm{kB}$ signaling in immune cells [12]. Interestingly, it has been shown that, under certain circumstances, other stimuli, including TNF, can to some extent also activate non-canonical NF- $\mathrm{KB}$ signaling in specific cell types [13], and IKK $\alpha$ is critical for interferon- $\alpha$ production induced by Toll-like receptors 7 and 9 [14]. The functional role of the non-canonical NF-кB pathway in vivo has been established by the identification of phenotypic abnormalities shared by knockout mice or mutants of specific signaling molecules involved in this pathway. Overall, this pathway is crucially involved in lymphoid organ development and adaptive immune responses [8]. The role of non-canonical NF- $\mathrm{B}$ signaling in (synovial) inflammation is addressed below.

\section{Non-canonical NF-KB signaling in rheumatoid arthritis}

In the inflamed RA synovial tissue, all stimuli that are able to induce non-canonical NF- $\mathrm{kB}$ signaling are abundantly present. LT $\beta$ plays an essential role in lymphoid organ development and it has been demonstrated that this is dependent on LT $\beta R$-induced non-canonical NF$\kappa \mathrm{B}$ activation (reviewed in [15]). In RA synovial tissue, tertiary lymphoid structures (TLSs) can be formed that often resemble germinal centers with organized B- and T-cell clusters. Of note, LT $\beta$ is also important in the formation of TLSs in RA synovitis [16]. Signaling through the LT $\beta R$ can also be induced by LIGHT and high levels of LIGHT have been observed in serum, synovial tissue, as well as in synovial fluid of RA patients [17]. In addition, LIGHT is upregulated on B cells and monocytes in RA peripheral blood and synovial fluid [18].

Activation of the non-canonical NF- $\mathrm{B}$ pathway can also be induced via BAFF/BAFF receptor (BAFF-R) or CD40L/CD40 triggering. CD40L is highly expressed in RA synovial tissue [19], and elevated in serum and peripheral blood of RA patients [20]. Furthermore, CD40L and CD40 are highly expressed by $\mathrm{T}$ lymphocytes and macrophages in the synovial fluid of RA patients [21]. In patients with RA, elevated serum levels of BAFF have been observed [22], and BAFF/BAFF-R are widely expressed in RA synovium [23].

Interaction of RANK and RANK ligand (RANKL) has been extensively studied in RA because of the important role in osteoclast biology. RANKL is highly expressed in synovial tissue of RA patients with active disease [24] and increased levels of soluble RANKL are found both in serum and synovial fluid from RA patients [25].

Together, these studies suggest that activators of the non-canonical NF- $\mathrm{B}$ b pathway play an important role in RA synovial inflammation, although direct involvement of the non-canonical NF- $\mathrm{kB}$ pathway is hitherto lacking. $\mathrm{Nik}^{-/-}$mice and aly/aly mice that are homozygous for a spontaneous recessive point mutation in the gene encoding NIK both lack lymph nodes and have a disturbed microarchitecture of the spleen. Furthermore, these mice have reduced humoral and cell-mediated immune functions, and are more susceptible to infections, although they do have mature $\mathrm{T}$ and $\mathrm{B}$ cells [26,27]. $\mathrm{Relb}^{-1-}$ mice develop a complex phenotype, including an autoimmune-like inflammatory syndrome, myeloid hyperplasia, multifocal defects in immune responses, and impaired development of lymphoid organs [28-30]. These studies demonstrate that the non-canonical NF- $\mathrm{kB}$ pathway controls the expression of genes involved in B-cell function and lymphoid organogenesis, as well as cell proliferation and survival. NIK has also been shown to be critical for inflammation-induced osteoclastogenesis, as NIKdeficient mice were largely resistant to arthritis with less osteoclastogenesis and less bone erosion [31]. Importantly, the non-canonical NF-kB pathway appears to play different roles in different cell types. Since many cell types are involved in the pathogenesis of RA, it is very difficult to predict the net overall contribution of non-canonical NF- $\mathrm{kB}$ signaling to synovial inflammation. Therefore, the role of the non-canonical NF- $k B$ pathway in the most important cell types involved in RA synovial inflammation is discussed below.

\section{Macrophages}

Inflamed RA synovial tissue contains many macrophages that contribute to inflammation, which is substantiated by our observation that the number of $\mathrm{CD}^{+} 8^{+}$synovial sublining macrophages correlates with clinical improvement independent of therapeutic strategy [32]. However, macrophages are phenotypically heterogeneous, and are not only the main producers of proinflammatory cytokines like TNF, IL-1, IL-15, IL-18, IL-23, and IL-27 that play an important role in the persistence of inflammation, but also generate inhibitory mediators such as IL-10, transforming growth factor- $\beta$, and soluble TNF receptor (reviewed in [33]). We and others have demonstrated that the canonical NF- $\mathrm{kB}$ pathway plays an important role in macrophage production of TNF- $\alpha$ and destructive MMPs [7]. The non-canonical NF- $\mathrm{kB}$ pathway is activated during human monocyte-macrophage differentiation and the increase in IKK $\alpha$ may act as a brake preventing hyperactivation of the new macrophages [34]. IKK $\alpha$ accelerates turnover of the classical NF- $\mathrm{kB}$ subunits RelA and c-Rel in macrophages, and their removal from pro-inflammatory gene promotors, thereby negatively regulating its own activation. Consequently, inactivation of IKK $\alpha$ in mice resulted in enhanced inflammation [11]. These data strongly suggest that the non-canonical NF- $\mathrm{kB}$ pathway plays a regulatory role in macrophages. In contrast to these findings, non-canonical NF- $\mathrm{B}$ signaling in macrophages is critical for production of the chemokine CXCL12, which is required for cells to migrate toward HMGB1, a 
proinflammatory cytokine and chemoattractant for immune effector cells [35].

The abundant presence of non-canonical NF- $\mathrm{BB}$ ligands in RA synovial tissue is likely to induce signaling in macrophages as well. LIGHT is expressed in CD68 ${ }^{+}$ macrophages and in vitro stimulation of these cells with LIGHT induced expression of MMP-9 and proinflammatory cytokines TNF- $\alpha$, IL-6, and IL-8 [36]. Synovial fluid macrophages express increased levels of CD40 and produce both IL-12p40, TNF- $\alpha$ and IL-10 after CD40 ligation [37]. However, the contribution of the non-canonical NF- $\mathrm{kB}$ pathway to these LIGHT- and CD40L-induced processes remains to be tested. In contrast to other leukocytes, macrophages are more long-lived cells and also persist at inflammatory lesions during the resolution of inflammation [38]. Therefore, the non-canonical NF-kB pathway may play a dual role in macrophages and can act as both a pro-inflammatory and an anti-inflammatory pathway.

\section{Dendritic cells}

In RA synovial tissue, immature and mature dendritic cell (DC) subsets can be observed in close association with $\mathrm{T}$ cells and B-cell follicles [39]. These DCs may contribute to ongoing inflammation through presentation of autoantigens or production of pro-inflammatory cytokines. $\mathrm{NF}-\mathrm{kB}$ is essential for normal DC differentiation, activation and survival [40]. CD40 ligation on DCs induces early production of inflammatory cytokines via the canonical NF- $\kappa B$ pathway, as well as late expression of the antiinflammatory enzyme indoleamine 2,3-dioxygenase via non-canonical NF- $\mathrm{kB}$ signaling, which is able to suppress $\mathrm{T}$-cell activation and to promote $\mathrm{T}$ cells with regulatory functions [41]. Interestingly, both synovial fluid and synovial tissues of RA patients contain DCs that express functional indoleamine 2,3-dioxygenase [42], pointing towards a possible mechanism of tolerance in RA synovial inflammation. These results are consistent with in vivo experiments performed in mice lacking functional NIK that have decreased numbers of DCs which also have lower expression of costimulatory molecules and exhibit reduced antigen presentation. Consequently, these DCs have a decreased ability to induce expansion of $\mathrm{CD} 25^{+} \mathrm{CD} 4^{+}$regulatory $\mathrm{T}$ cells [43]. At the same time, it was demonstrated that DCs require non-canonical NF- $\kappa B$ signaling to crossprime $\mathrm{CD}^{+}{ }^{+} \mathrm{T}$ cells [44]. Furthermore, NIK expression in mouse DCs is also important for supplying co-stimulatory signals to $\mathrm{CD}^{+}{ }^{+} \mathrm{T}$ cells [45]. In human DCs, however, NIK was not essential for effective antigen presentation [46].

Taken together, the non-canonical NF-kB pathway regulates both pro-inflammatory and anti-inflammatory processes in DCs. The net result is likely to rely heavily on additional stimuli and the microenvironment in which the cells are present.

\section{B cells and plasma cells}

$B$ cells are present in the inflamed RA synovial tissue and the efficacy of anti-CD20 treatment has confirmed the pivotal role of $\mathrm{B}$ cells in the pathogenesis of RA in patients [47]. The canonical NF- $\mathrm{B}$ pathway was originally described in B cells and is crucial for B-cell development, maintenance, and function (reviewed in [48]). However, the non-canonical pathway also plays an important role in B-cell biology. IKK $\alpha$ in B cells is crucial for germinal center formation, and long-lived immunoglobin titers, but not for primary antibody production [49]. Importantly, NIK also regulates BAFF-mediated expression of inducible costimulator ligand, a molecule required for follicular helper $\mathrm{T}$ cell generation [50]. In addition, NIK provides survival signals in B cells, which is illustrated by the fact that B cell-specific ablation of TRAF2 and TRAF3 (negative regulators of NIK) markedly enhanced the survival and proliferation of $B$ cells [51]. Furthermore, non-canonical NF- $\mathrm{kB}$ signaling also regulates plasma cell generation, proliferation and survival [52]. In conclusion, the non-canonical pathway plays an important role in B cells and plasma cells by promoting survival, differentiation and antibody production, which is likely to contribute to the persistence of inflammation in RA.

\section{T cells}

Many T cell subsets can be found in RA synovial tissue, including Th1, Th17 and regulatory $\mathrm{T}$ cells (reviewed in [53]). The canonical NF-kB pathway is well known for its role in the activation and differentiation of $\mathrm{T}$ cells [54]. In contrast, the role of the non-canonical NF- $\kappa B$ pathway in T-cell function is less well studied. It has been shown that NIK and RelB are essential for T-cell activation via the T-cell receptor/CD3 pathway [55]. NIK and IKK $\alpha$ have a T-cell-intrinsic function in the regulation of Th17 cells, a subset of $\mathrm{CD} 4^{+}$effector $\mathrm{T}$ cells that produce the IL17 family of cytokines, which are intimately involved in autoimmunity, including in RA [56,57]. The non-canonical $\mathrm{NF}-\mathrm{kB}$ pathway is also required for the generation of $\mathrm{CD} 4^{+}$ $\mathrm{T}$-follicular helper cells mediating B-cell activation and antibody responses [50]. In contrast, NIK is essential for the generation of regulatory $\mathrm{T}$ cells that dampen inflammatory responses as well [58].

In summary, the non-canonical NF- $\mathrm{kB}$ pathway has dual roles in T cells; it is not only important in T-cell activation and the induction of Th17 cells, but is also required for the generation of regulatory $\mathrm{T}$ cells.

\section{Osteoclasts}

In RA synovial tissue, osteoclasts that resorb bone are found at sites adjacent to bone, causing local bone destruction [59]. Interestingly, aly/aly mice that lack functional NIK have increased bone mineral density and bone volume. In addition, these mice and $\mathrm{Nik}^{-1-}$ mice 
have a significant defect in RANKL-induced osteoclastogenesis in vitro and in vivo [60,61]. Also, $\mathrm{Nik}^{-1-}$ mice exhibit significantly less periarticular osteoclastogenesis and less bone erosion in the serum transfer arthritis model [31]. Interestingly, overexpression of constitutively active IKK $\alpha$ or p52 restored osteoclastogenesis in aly/aly cells [60] and re-introduction of RelB, but not p65, in relb ${ }^{-/-}$ cells rescued osteoclast formation [62]. Activated osteoclasts are responsible for the bone loss associated with RA. Constitutive activation of NIK drives enhanced osteoclastogenesis and bone resorption, both in basal conditions and in response to inflammatory stimuli [63]. In humans, RANKL expressed by synovial fibroblasts [64] or $\mathrm{T}$ cells [65] effectively induces osteoclastogenesis. Also, IKK $\alpha$ is required for RANKL-induced osteoclast formation in vitro [66]. In conclusion, non-canonical NF- $\mathrm{kB}$ signaling in osteoclasts unambiguously contributes to bone destruction in RA, suggesting that this pathway may be an interesting target in these cells.

\section{Synovial fibroblasts}

RA synovial fibroblasts (RASFs) create an abnormal stromal microenvironment that is thought to be crucial for the persistence of inflammation, not only because of its architecture, but also by secreting pro-inflammatory cytokines or by producing growth factors that stimulate neovascularization. In addition, it has been demonstrated that RASFs display certain unique features, such as an invasive, tumor-like behavior that is normally not observed in fibroblasts (reviewed in [67]). Non-canonical NF- $\mathrm{BB}$ signaling contributes to inflammation in RASFs since NIK is essential for LT $\beta R$ activation of NF- $\mathrm{BB}$ in these cells [68]. Also, stromal cells from mice lacking functional NIK showed decreased levels of adhesion molecules and increased CXCL13 expression. These findings suggest that NIK activity in stromal cells may play an important role in regulating the migration of immune cells [69]. Stimulation of RASFs with LIGHT results in upregulation of adhesion molecules and MMPs [18]. Also, CD40 ligation of RASFs induces RANKL expression, resulting in enhanced osteoclast formation [64]. Stimulation of RASFs with CD40L also induces the non-canonical pathway target gene CXCL12, which may promote angiogenesis and the migration of T cells, B cells, and monocytes/macrophages into the inflamed synovium [70].

In summary, non-canonical NF- $\mathrm{kB}$ signaling in RASFs contributes to the pathological behavior of these cells, leading to persistence of inflammation.

\section{Endothelial cells}

Endothelial cells (ECs) play a crucial role in the pathogenesis of RA. First, they express adhesion molecules and produce chemokines, thereby acting as the site of entry for immune cells into the synovial tissue. In addition, ECs proliferate and give rise to neovascularization that contributes to the persistence of inflammation (reviewed in [71]). In synovial tissue containing TLSs, highly differentiated ECs, such as high endothelial venules, can also be observed [16]. Consequently, the signaling pathways that control activation of ECs have been extensively studied and the canonical NF- $\mathrm{KB}$ pathway was demonstrated to play an important role in the expression of many of the pro-inflammatory genes [72]. Madge and colleagues [73] reported that LIGHT and LT $\alpha 1 \beta 2$, but not TNF, induce CXCL12 expression in ECs, which required non-canonical NF- $\mathrm{kB}$ signaling. CXCL12 expression in ECs has been demonstrated in RA synovial tissue as well [74]. In addition, CXCL12 colocalized with $\alpha_{\mathrm{v}} \beta_{3}$, a marker for neoangiogenesis, in RA ECs, which would suggest that CXCL12 may be involved in RA synovial tissue angiogenesis [74]. We have observed that CXCL12 is expressed by $\mathrm{NIK}^{+}$blood vessels in RA synovial tissue. Subsequently, we established that non-canonical NF- $\mathrm{kB}$ signaling in ECs stimulates pathological angiogenesis [75]. Recently, it was demonstrated that EC-specific LT $\beta R$ signaling is crucial for lymph node and high endothelial venule formation in mice, designating ECs as an important player in organizing lymphoid tissue [76]. Unpublished results from our group further support these data, as we observed high numbers of $\mathrm{NIK}^{+}$ECs in TLSs in RA synovial tissue and correlated this with the presence of perivascular (pre-) follicular dendritic cells. This suggests that these cells may be important in the formation of TLSs in chronic inflammation (Noort et al., unpublished observations).

In summary, non-canonical NF- $\mathrm{kB}$ signaling in ECs is likely to contribute to angiogenesis and the influx of immune cells into the inflamed RA synovial tissue, thereby perpetuating the inflammatory response. Therefore, blocking this pathway in ECs is probably beneficial in RA.

\section{Targeting the non-canonical NF-KB pathway in rheumatoid arthritis}

Despite the diverse roles of the non-canonical NF- $\mathrm{kB}$ pathway in different cell types, overall this pathway is likely to contribute to the persistence of inflammation in RA. As alluded to earlier, non-canonical NF- $\mathrm{kB}$ signaling can be induced via triggering of various TNF-receptor superfamily members, such as LT $\beta R$, CD40, BAFF-R, and RANK, by their respective ligands. The important role of these ligand-receptor pairs in (synovial) inflammation is illustrated by the numerous attempts of pharmaceutical companies to target these pathways. Below, we will discuss compounds that have been tested in RA patients or preclinical models of RA (Table 1).

\section{Anti-BAFF/BAFF-R treatment}

Belimumab, a fully human IgG1 monoclonal antibody to BAFF, was tested in RA in a phase II placebo-controlled 
Table 1 Biologics targeting ligand-receptor pairs involved in non-canonical nuclear factor-KB signaling in rheumatoid arthritis

\begin{tabular}{|c|c|c|c|c|c|}
\hline Ligand & Receptor & Biologic & Type of agent & Activity of biologic & Stage of development \\
\hline \multirow[t]{2}{*}{ BAFF } & BAFF-R & $\begin{array}{l}\text { Belimumab (Benlysta; Human Genome } \\
\text { Sciences/GlaxoSmithKline) }\end{array}$ & Human BAFF-specific antibody & Antagonist & Phase II \\
\hline & & Tabalumab/LY2127399 & Human BAFF-specific antibody & Antagonist & Phase II \\
\hline CD40L & CD40 & Bl 655064 & Humanized CD40-specific antibody & Antagonist & Phase I in progress \\
\hline - & LTßR & Baminercept & Human $L T \beta R-\lg G_{1}$ fusion protein & Antagonist & Phase II \\
\hline LTa & $L T \beta R$ & Patecluzimab & Humanized LTa-specific antibody & Depleting and antagonist & Phase II in progress \\
\hline RANKL & RANK & Denosumab (Prolia/Xgeva; Amgen) & Human RANKL-specific antibody & Antagonist & Phase II \\
\hline
\end{tabular}

BAFF, B cell activating factor; BAFF-R, BAFF receptor; CD40L, CD40 ligand; lg, immunoglobulin; LTa, lymphotoxin- $\alpha$; LT $\beta R$, LT $\beta$ receptor; RANK, receptor activator of nuclear factor-KB; RANKL, RANK ligand.

dose-ranging trial. Due to the modest clinical response in this trial, it was not further tested for RA [77]. However, belimumab has been proven to have a beneficial clinical effect in systemic lupus erythematosus (SLE) patients and is licensed for use in SLE in the United States, Canada, and Europe. A different anti-BAFF monoclonal antibody, tabalumab, has also been tested in patients with active RA. This drug showed modest efficacy [78], but nevertheless clinical development in RA was discontinued.

\section{Anti-CD40/CD40L treatment}

Clinical trials targeting the CD40/CD40L interaction in RA are currently ongoing, but so far have not been published. However, animal models have demonstrated encouraging results. In the collagen-induced arthritis (CIA) model, treatment with agonistic CD40 antibodies at the time of CIA induction exacerbates disease [79]. In contrast, treatment with anti-CD40L antibodies prior to CIA induction ameliorated development of disease [80], resulting in less synovial inflammation, and less bone erosion [81]. In humans, two clinical studies investigating the effects of anti-CD40L treatment have been conducted in patients with SLE. Both ruplizumab and toralizumab showed promising clinical and laboratory responses in some SLE patients. However, one of these studies was discontinued prematurely because of thromboembolic events [82]. Since then, new reagents inhibiting CD40Lmediated events that are less likely to increase the risk of thromboembolic complications have been developed and clinical trials in RA patients are in progress.

\section{Anti-LT $\beta / L T \beta R$ treatment}

In the collagen-induced arthritis model, treatment with a LT $\beta R$-Ig fusion protein resulted in reductions in the severity of disease and joint tissue damage [83].

The efficacy and safety of baminercept, a LT $\beta R-\operatorname{IgG}_{1}$ fusion protein, was evaluated in patients with RA in a placebo-controlled, phase IIb trial [84]. However, baminercept did not exhibit measurable clinical effects in RA patients. Pateclizumab, a humanized mouse antibody that specifically binds LT $\alpha$ in both the soluble LT $\alpha 3$ homotrimeric form and the surface-expressed LT $\alpha 1 \beta 2$ heterotrimer, thereby interfering with binding of LT trimers to their cognate receptors, was tested for safety and efficacy in a phase I study. Preliminary beneficial effects were observed in RA patients [85] and a phase II trial to further test pateclizumab is now in progress.

\section{Anti-RANK/RANKL treatment}

In mice, treatment with a neutralizing anti-RANKL monoclonal antibody in CIA resulted in amelioration of bone loss [86]. Phase II clinical trials suggest that denosumabmediated inhibition of RANKL in RA patients prevents bone loss at the site of inflammation, but has no apparent effect on inflammation [87]. Nevertheless, denosumab could be used as an adjunctive therapy next to established (biologic) disease-modifying antirheumatic drugs to prevent structural joint damage in RA.

One has to bear in mind that virtually all stimuli that activate TNF receptor superfamily members and induce non-canonical pathway signaling simultaneously also activate the canonical pathway. Hence, determining whether the observed therapeutic effects of blocking these receptor-ligand pairs are mediated via inhibition of the non-canonical pathway or can also be attributed to effects on canonical NF- $\mathrm{kB}$ signaling is difficult and requires further investigation.

\section{Future perspectives: direct targeting of intracellular signaling molecules}

Rather than indirect inhibition of non-canonical NF- $\mathrm{kB}$ signaling using the compounds described above, direct inhibition of NIK or IKK $\alpha$ may be more effective. In RA synovial inflammation, NIK can be targeted using intraarticular gene therapy (Noort et al., unpublished, ongoing studies in preclinical models of arthritis) or using small molecule inhibitors. Since NIK levels in normal cells are usually low, it is anticipated that therapeutics designed to limit the amount of NIK will not cause serious side effects. Consequently, NIK inhibition using 
specific small molecule inhibitors could perhaps be an effective treatment option not only for RA but also for other chronic inflammatory diseases. Recently, a report was published in which the discovery, structure-based design, synthesis, and optimization of several selective NIK inhibitors are described [88]. So far, only one specific IKK $\alpha$ inhibitor, BAY32-5915, has been reported [89]. We expect that preclinical studies will soon answer the question of whether selective targeting of NIK or $\mathrm{IKK} \alpha$ and consecutive non-canonical NF- $\mathrm{KB}$ signaling may be beneficial in (rheumatoid) arthritis as well. Alternatively, in some cell types it may be beneficial to actually stimulate non-canonical NF- $\mathrm{kB}$ activity to obtain a therapeutic effect. Smac mimetics or inhibitor of apoptosis protein antagonists that promote degradation of cIAP1 and cIAP2 are not only able to induce apoptosis in cancer cells, but also promote stabilization of NIK and consequent activation of the non-canonical NF- $\mathrm{kB}$ pathway in resting cells $[90,91]$. Currently, one of these smac mimetic compounds, called Birinapant, is undergoing clinical development for the treatment of solid tumors and hematological malignancies [92,93].

\section{Conclusion}

The studies reviewed above support the role of the noncanonical NF- $\mathrm{kB}$ pathway as a major participant in inflammatory responses in general and the pathogenesis of
RA in particular. NIK and downstream non-canonical NF$\mathrm{\kappa B}$ signaling have diverse functions, depending on the cell types in which this pathway is activated. Roughly, in synovial fibroblasts, osteoclasts, endothelial cells, and B cells/ plasma cells, non-canonical NF- $\mathrm{kB}$ signaling contributes to the inflammatory process by triggering the secretion of critical inflammatory mediators and matrix-degrading enzymes involved in tissue degradation, whereas in macrophages, dendritic cells and T cells this pathway has more pleiotropic functions and can also play a more regulatory, anti-inflammatory role (Figure 2). In these cells noncanonical NF-kB signaling shows clear resemblance with 'The Strange Case of Dr Jekyll and Mr Hyde' (Robert Louis Stevenson): there is a good and an evil side. Further elucidation of the precise function of this pathway in individual cell types will result in a better understanding of the overall contribution of the non-canonical NF- $\mathrm{KB}$ pathway to the complex cellular networks involved in RA synovial inflammation. This will allow the design of better therapeutic strategies for the management of this disease, including cell type-specific inhibitors or selective targeting of inhibitors to certain cell types. For this application, anti-DEC-205 antibodies may be used to target compounds specifically to DCs or to selectively target ECs, and (peptide) inhibitors can be coupled to a multimodular recombinant protein that specifically binds to cytokineactivated endothelium, which has been demonstrated to

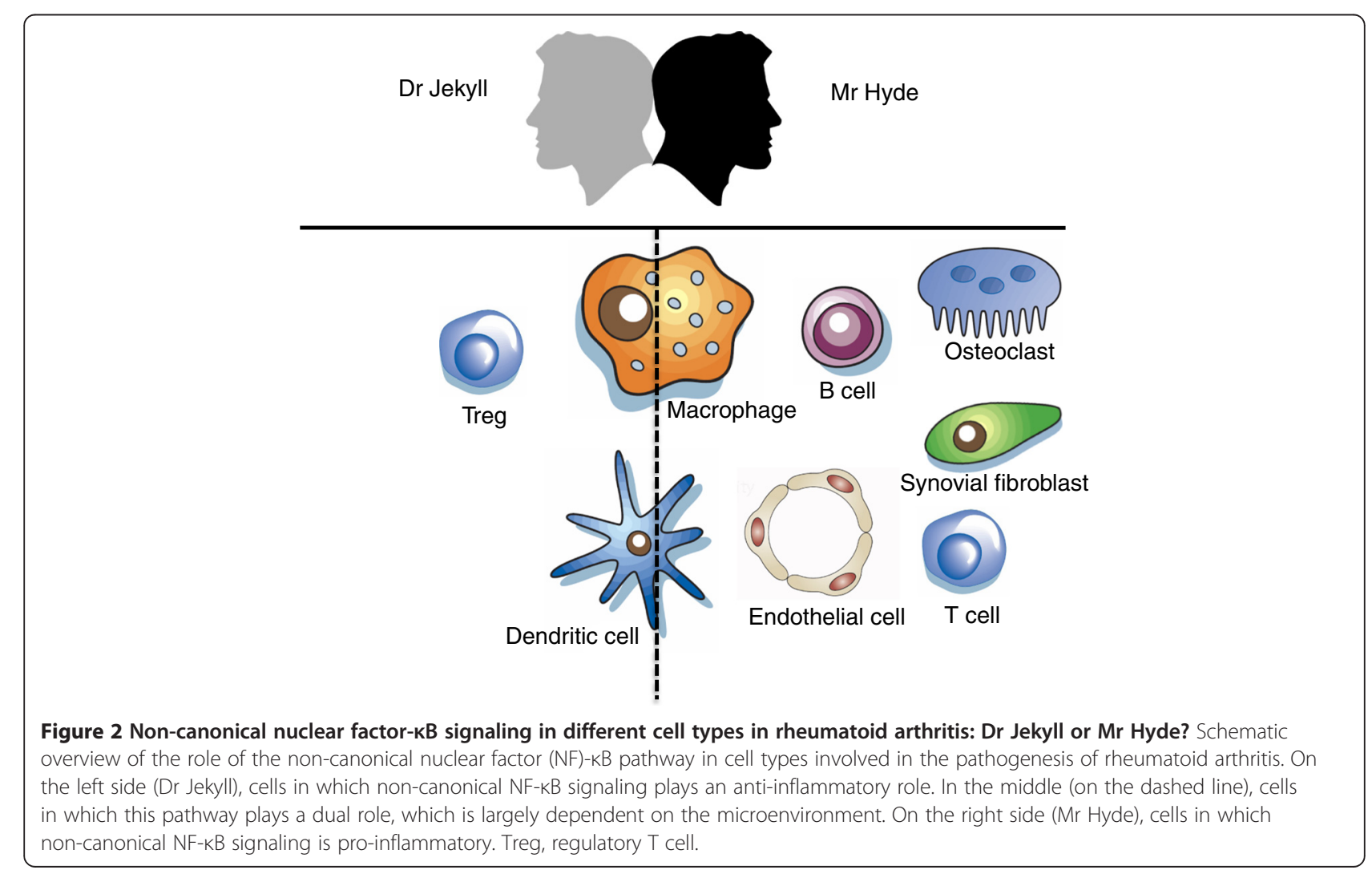


work very elegantly under inflammatory conditions in vivo [94].

Although the non-canonical NF- $\mathrm{kB}$ pathway has antiinflammatory effects in some cell types, we believe that in chronic inflammation the positive effects of targeting the non-canonical NF- $\mathrm{kB}$ pathway will surpass the possible negative effects. We anticipate that the advent of several selective NIK inhibitors will aid in further establishing the non-canonical NF- $\mathrm{kB}$ pathway as a promising new therapeutic target, not only in RA, but also in other immune-mediated inflammatory diseases.

\section{Abbreviations}

BAFF: B cell activating factor; BAFF-R: B cell activating factor receptor; CIA: Collagen-induced arthritis; DC: Dendritic cell; EC: Endothelial cell; IKK: Inhibitor of KB kinase; IL: Interleukin; LTß: Lymphotoxin B; LTßR: Lymphotoxin $\beta$ receptor; MMP: Matrix metalloproteinase; NF-kB: Nuclear factor-kB; NIK: NF-kB inducing kinase; RA: Rheumatoid arthritis; RANK: Receptor activator of NF-kB; RANKL: Receptor activator of NF-KB ligand; RASF: Rheumatoid arthritis synovial fibroblast; SLE: Systemic lupus erythematosus; TLS: Tertiary lymphoid structure; TNF: Tumor necrosis factor.

\section{Competing interests}

The authors declare that they have no competing interests.

\section{Acknowledgements}

SWT was supported by a VENI grant and a Clinical Fellowship from the Netherlands Organisation for Scientific Research (NWO/ZonMw). ARN was supported by an institutional grant of the Academic Medical Center.

\section{Author details}

'Department of Clinical Immunology \& Rheumatology, Academic Medical Center/University of Amsterdam, 1105AZ Amsterdam, The Netherlands. 2Department of Experimental Immunology, Academic Medical Center/ University of Amsterdam, 1105 AZ Amsterdam, The Netherlands.

${ }^{3}$ Department of Medicine, University of Cambridge, Cambridge CB2 1TN, UK.

${ }^{4}$ Current address: GlaxoSmithKline, Stevenage SG1 2NY, UK.

Published online: 28 January 2015

\section{References}

1. Mclnnes IB, Schett $G$. The pathogenesis of rheumatoid arthritis. N Engl J Med. 2011;365:2205-19.

2. Tas SW, Remans PH, Reedquist KA, Tak PP. Signal transduction pathways and transcription factors as therapeutic targets in inflammatory disease: towards innovative antirheumatic therapy. Curr Pharm Des. 2005;11:581-611.

3. Tak PP, Firestein GS. NF-kappaB: a key role in inflammatory diseases. J Clin Invest. 2001;107:7-11.

4. Vallabhapurapu S, Karin M. Regulation and function of NF-kappaB transcription factors in the immune system. Annu Rev Immunol. 2009;27:693-733.

5. Ben-Neriah Y, Karin M. Inflammation meets cancer, with NF-kappaB as the matchmaker. Nat Immunol. 2011;12:715-23.

6. Tak PP, Gerlag DM, Aupperle KR, van de Geest DA, Overbeek M, Bennett BL, et al. Inhibitor of nuclear factor kappaB kinase beta is a key regulator of synovial inflammation. Arthritis Rheum. 2001;44:1897-907.

7. Tas SW, Vervoordeldonk MJ, Hajji N, May MJ, Ghosh S, Tak PP. Local treatment with the selective IkappaB kinase beta inhibitor NEMO-binding domain peptide ameliorates synovial inflammation. Arthritis Res Ther. 2006;8:R86.

8. Sun SC. The noncanonical NF-kappaB pathway. Immunol Rev. 2012;246:125-40.

9. Anest V, Hanson JL, Cogswell PC, Steinbrecher KA, Strahl BD, Baldwin AS. A nucleosomal function for IkappaB kinase-alpha in NF-kappaB-dependent gene expression. Nature. 2003;423:659-63.

10. Yamamoto Y, Verma UN, Prajapati S, Kwak YT, Gaynor RB. Histone H3 phosphorylation by IKK-alpha is critical for cytokine-induced gene expression. Nature. 2003;423:655-9.
11. Lawrence T, Bebien M, Liu GY, Nizet V, Karin M. IKKalpha limits macrophage NF-kappaB activation and contributes to the resolution of inflammation. Nature. 2005;434:1138-43.

12. Gray CM, Remouchamps C, McCorkell KA, Solt LA, Dejardin E, Orange JS, et al. Noncanonical NF-kappaB signaling is limited by classical NF-kappaB activity. Sci Signal. 2014;7:ra13.

13. Zhang $\mathrm{H}$, Hilton MJ, Anolik JH, Welle SL, Zhao C, Yao Z, et al. NOTCH inhibits osteoblast formation in inflammatory arthritis via noncanonical NF-kappaB. J Clin Invest. 2014;124:3200-14.

14. Hoshino K, Sugiyama T, Matsumoto M, Tanaka T, Saito M, Hemmi H, et al. IkappaB kinase-alpha is critical for interferon-alpha production induced by Toll-like receptors 7 and 9. Nature. 2006;440:949-53.

15. Mebius RE. Organogenesis of lymphoid tissues. Nat Rev Immunol. 2003:3:292-303.

16. Takemura S, Braun A, Crowson C, Kurtin PJ, Cofield RH, O'Fallon WM, et al. Lymphoid neogenesis in rheumatoid synovitis 4. J Immunol. 2001;167:1072-80.

17. Pierer M, Brentano F, Rethage J, Wagner U, Hantzschel H, Gay RE, et al. The TNF superfamily member LIGHT contributes to survival and activation of synovial fibroblasts in rheumatoid arthritis 1. Rheumatology. 2007:46:1063-70.

18. Kang YM, Kim SY, Kang JH, Han SW, Nam EJ, Kyung HS, et al. LIGHT up-regulated on B lymphocytes and monocytes in rheumatoid arthritis mediates cellular adhesion and metalloproteinase production by synoviocytes. Arthritis Rheum. 2007;56:1106-17.

19. Kang YM, Zhang X, Wagner UG, Yang H, Beckenbaugh RD, Kurtin PJ, et al. CD8 T cells are required for the formation of ectopic germinal centers in rheumatoid synovitis. J Exp Med. 2002;195:1325-36.

20. MacDonald KP, Nishioka Y, Lipsky PE, Thomas R. Functional CD40 ligand is expressed by T cells in rheumatoid arthritis. J Clin Invest. 1997;100:2404-14.

21. Liu MF, Chao SC, Wang CR, Lei HY. Expression of CD40 and CD40 ligand among cell populations within rheumatoid synovial compartment. Autoimmunity. 2001;34:107-13.

22. Ng LG, Mackay CR, Mackay F. The BAFF/APRIL system: life beyond B lymphocytes. Mol Immunol. 2005;42:763-72.

23. Nakajima $K$, Itoh $K$, Nagatani $K$, Okawa-Takatsuji M, Fujii T, Kuroki $H$, et al Expression of BAFF and BAFF-R in the synovial tissue of patients with rheumatoid arthritis. Scand J Rheumatol. 2007;36:365-72.

24. Haynes DR, Barg E, Crotti TN, Holding C, Weedon H, Atkins GJ, et al. Osteoprotegerin expression in synovial tissue from patients with rheumatoid arthritis, spondyloarthropathies and osteoarthritis and normal controls. Rheumatology. 2003;42:123-34.

25. Ellabban AS, Kamel SR, Ahmed SS, Osman AM. Receptor activator of nuclear factor kappa B ligand serum and synovial fluid level. A comparative study between rheumatoid arthritis and osteoarthritis. Rheumatol Int. 2012;32:1589-96.

26. Miyawaki S, Nakamura Y, Suzuka H, Koba M, Yasumizu R, Ikehara S, et al. A new mutation, aly, that induces a generalized lack of lymph nodes accompanied by immunodeficiency in mice. Eur J Immunol. 1994;24:429-34.

27. Yin L, Wu L, Wesche H, Arthur CD, White JM, Goeddel DV, et al. Defective lymphotoxin-beta receptor-induced NF-kappaB transcriptional activity in NIK-deficient mice. Science. 2001;291:2162-5.

28. Weih F, Warr G, Yang H, Bravo R. Multifocal defects in immune responses in RelB-deficient mice. J Immunol. 1997;158:5211-8.

29. Weih DS, Yilmaz ZB, Weih F. Essential role of RelB in germinal center and marginal zone formation and proper expression of homing chemokines. J Immunol. 2001;167:1909-19.

30. Weih F, Carrasco D, Durham SK, Barton DS, Rizzo CA, Ryseck RP, et al. Multiorgan inflammation and hematopoietic abnormalities in mice with a targeted disruption of RelB, a member of the NF-kappa B/Rel family. Cell. 1995:80:331-40.

31. Aya K, Alhawagri M, Hagen-Stapleton A, Kitaura H, Kanagawa O, Novack DV. NF-(kappa)B-inducing kinase controls lymphocyte and osteoclast activities in inflammatory arthritis. J Clin Invest. 2005;115:1848-54.

32. Bresnihan B, Pontifex E, Thurlings RM, Vinkenoog M, El-Gabalawy H, Fearon $U$, et al. Synovial tissue sublining CD68 expression is a biomarker of therapeutic response in rheumatoid arthritis clinical trials: consistency across centers. J Rheumatol. 2009;36:1800-2.

33. Hamilton JA, Tak PP. The dynamics of macrophage lineage populations in inflammatory and autoimmune diseases. Arthritis Rheum. 2009;60:1210-21.

34. Li T, Morgan MJ, Choksi S, Zhang Y, Kim YS, Liu ZG. MicroRNAs modulate the noncanonical transcription factor NF-kappaB pathway by regulating expression of the kinase IKKalpha during macrophage differentiation. Nat Immunol. 2010;11:799-805. 
35. Kew RR, Penzo M, Habiel DM, Marcu KB. The IKKalpha-dependent NFkappaB p52/RelB noncanonical pathway is essential to sustain a CXCL12 autocrine loop in cells migrating in response to HMGB1. J Immunol. 2012;188:2380-6.

36. Kim WJ, Kang YJ, Koh EM, Ahn KS, Cha HS, Lee WH. LIGHT is involved in the pathogenesis of rheumatoid arthritis by inducing the expression of pro-inflammatory cytokines and MMP-9 in macrophages. Immunology. 2005:114:272-9.

37. Mottonen M, Isomaki P, Luukkainen R, Lassila O. Regulation of CD154induced interleukin-12 production in synovial fluid macrophages. Arthritis Res. 2002;4:R9.

38. Buckley CD, Gilroy DW, Serhan CN, Stockinger B, Tak PP. The resolution of inflammation. Nat Rev Immunol. 2013;13:59-66.

39. Lebre MC, Jongbloed SL, Tas SW, Smeets TJ, Mclnnes IB, Tak PP. Rheumatoid arthritis synovium contains two subsets of CD83-DC. Am J Pathol. 2008;172:940-50.

40. Tas SW, de Jong EC, Hajji N, May MJ, Ghosh S, Vervoordeldonk MJ, et al. Selective inhibition of NF-kappaB in dendritic cells by the NEMO-binding domain peptide blocks maturation and prevents T cell proliferation and polarization. Eur J Immunol. 2005;35:1164-74.

41. Tas SW, Vervoordeldonk MJ, Hajji N, Schuitemaker JH, van der Sluijs KF, May $\mathrm{MJ}$, et al. Noncanonical NF-kappaB signaling in dendritic cells is required for indoleamine 2,3-dioxygenase (IDO) induction and immune regulation. Blood. 2007;110:1540-9.

42. Zhu L, Ji F, Wang Y, Zhang Y, Liu Q, Zhang JZ, et al. Synovial autoreactive $T$ cells in rheumatoid arthritis resist IDO-mediated inhibition. J Immunol. 2006;177:8226-33.

43. Tamura C, Nakazawa M, Kasahara M, Hotta C, Yoshinari M, Sato F, et al. Impaired function of dendritic cells in alymphoplasia (aly/aly) mice for expansion of CD25 + CD4+ regulatory T cells. Autoimmunity. 2006:39:445-53.

44. Lind EF, Ahonen CL, Wasiuk A, Kosaka Y, Becher B, Bennett KA, et al. Dendritic cells require the NF-kappaB2 pathway for cross-presentation of soluble antigens. J Immunol. 2008;181:354-63.

45. Hofmann J, Mair F, Greter M, Schmidt-Supprian M, Becher B. NIK signaling in dendritic cells but not in T cells is required for the development of effector T cells and cell-mediated immune responses. J Exp Med. 2011;208:1917-29.

46. Andreakos E, Smith C, Monaco C, Brennan FM, Foxwell BM, Feldmann M. Ikappa B kinase 2 but not NF-kappa B-inducing kinase is essential for effective DC antigen presentation in the allogeneic mixed lymphocyte reaction. Blood. 2003;101:983-91.

47. Boumans MJ, Thurlings RM, Gerlag DM, Vos K, Tak PP. Response to rituximab in patients with rheumatoid arthritis in different compartments of the immune system. Arthritis Rheum. 2011;63:3187-94.

48. Kaileh M, Sen R. NF-kappaB function in B lymphocytes. Immunol Rev. 2012:246:254-71.

49. Mills DM, Bonizzi G, Karin M, Rickert RC. Regulation of late B cell differentiation by intrinsic IKKalpha-dependent signals. Proc Natl Acad Sc U S A. 2007;104:6359-64.

50. Hu H, Wu X, Jin W, Chang M, Cheng X, Sun SC. Noncanonical NF-kappaB regulates inducible costimulator (ICOS) ligand expression and T follicular helper cell development. Proc Natl Acad Sci U S A. 2011;108:12827-32.

51. Gardam S, Sierro F, Basten A, Mackay F, Brink R. TRAF2 and TRAF3 signal adapters act cooperatively to control the maturation and survival signals delivered to B cells by the BAFF receptor. Immunity. 2008;28:391-401.

52. McCarthy BA, Yang L, Ding J, Ren M, King W, ElSalanty M, et al. NF-kappaB2 mutation targets survival, proliferation and differentiation pathways in the pathogenesis of plasma cell tumors. BMC Cancer. 2012;12:203.

53. Cope AP. T cells in rheumatoid arthritis. Arthritis Res Ther. 2008;10:S1.

54. Gerondakis S, Siebenlist U. Roles of the NF-kappaB pathway in lymphocyte development and function. Cold Spring Harb Perspect Biol. 2010;2:a000182.

55. Ishimaru N, Kishimoto H, Hayashi Y, Sprent J. Regulation of naive T cell function by the NF-kappaB2 pathway. Nat Immunol. 2006;7:763-72.

56. Maddur MS, Miossec P, Kaveri SV, Bayry J. Th17 cells: biology, pathogenesis of autoimmune and inflammatory diseases, and therapeutic strategies. Am J Pathol. 2012;181:8-18.

57. Li L, Ruan Q, Hilliard B, Devirgiliis J, Karin M, Chen YH. Transcriptional regulation of the Th17 immune response by IKK(alpha). J Exp Med. 2011:208:787-96.

58. Kajiura F, Sun S, Nomura T, Izumi K, Ueno T, Bando Y, et al. NF-kappa B-inducing kinase establishes self-tolerance in a thymic stroma-dependent manner. J Immunol. 2004;172:2067-75.
59. Schett G. Cells of the synovium in rheumatoid arthritis. Osteoclasts. Arthritis Res Ther. 2007:9:203.

60. Maruyama T, Fukushima H, Nakao K, Shin M, Yasuda H, Weih F, et al. Processing of the NF-kappa B2 precursor p100 to p52 is critical for RANKLinduced osteoclast differentiation. J Bone Miner Res. 2010;25:1058-67.

61. Novack DV, Yin L, Hagen-Stapleton A, Schreiber RD, Goeddel DV, Ross FP, et al. The IkappaB function of NF-kappaB2 p100 controls stimulated osteoclastogenesis. J Exp Med. 2003;198:771-81.

62. Vaira S, Johnson T, Hirbe AC, Alhawagri M, Anwisye I, Sammut B, et al. RelB is the NF-kappaB subunit downstream of NIK responsible for osteoclast differentiation. Proc Natl Acad Sci U S A. 2008;105:3897-902.

63. Yang C, McCoy K, Davis JL, Schmidt-Supprian M, Sasaki Y, Faccio R, et al. NIK stabilization in osteoclasts results in osteoporosis and enhanced inflammatory osteolysis. PLoS One. 2010;5:e15383.

64. Lee HY, Jeon HS, Song EK, Han MK, Park SI, Lee SI, et al. CD40 ligation of rheumatoid synovial fibroblasts regulates RANKL-mediated osteoclastogenesis: evidence of NF-kappaB-dependent, CD40-mediated bone destruction in rheumatoid arthritis. Arthritis Rheum. 2006:54:1747-58.

65. Miranda-Carus ME, Benito-Miguel M, Balsa A, Cobo-lbanez T, Perez de Ayala C, Pascual-Salcedo D, et al. Peripheral blood T lymphocytes from patients with early rheumatoid arthritis express RANKL and interleukin-15 on the cell surface and promote osteoclastogenesis in autologous monocytes. Arthritis Rheum. 2006:54:1151-64

66. Ruocco MG, Maeda S, Park JM, Lawrence T, Hsu LC, Cao Y, et al. I\{kappa\}B kinase (IKK)\{beta\}, but not IKK\{alpha\}, is a critical mediator of osteoclast survival and is required for inflammation-induced bone loss. J Exp Med. 2005;201:1677-87

67. Bartok B, Firestein GS. Fibroblast-like synoviocytes: key effector cells in rheumatoid arthritis. Immunol Rev. 2010;233:233-55.

68. Smith C, Andreakos E, Crawley JB, Brennan FM, Feldmann M, Foxwell BM NF-kappaB-inducing kinase is dispensable for activation of NF-kappaB in inflammatory settings but essential for lymphotoxin beta receptor activation of NF-kappaB in primary human fibroblasts. J Immunol. 2001;167:5895-903.

69. Kunisawa J, Gohda M, Kurashima Y, Ishikawa I, Higuchi M, Kiyono H. Sphingosine 1-phosphate-dependent trafficking of peritoneal B cells requires functional NFkappaB-inducing kinase in stromal cells. Blood. 2008;111:4646-52.

70. Kim KW, Cho ML, Kim HR, Ju JH, Park MK, Oh HJ, et al. Up-regulation of stromal cell-derived factor 1 (CXCL12) production in rheumatoid synovial fibroblasts through interactions with T lymphocytes: role of interleukin-17 and CD40L-CD40 interaction. Arthritis Rheum. 2007;56:1076-86.

71. Szekanecz Z, Besenyei T, Szentpetery A, Koch AE. Angiogenesis and vasculogenesis in rheumatoid arthritis. Curr Opin Rheumatol. 2010;22:299-306.

72. De MR, Hoeth M, Hofer-Warbinek R, Schmid JA. The transcription factor NF-kappa B and the regulation of vascular cell function. Arterioscler Thromb Vasc Biol. 2000;20:E83-8.

73. Madge LA, Kluger MS, Orange JS, May MJ. Lymphotoxin-alpha 1 beta 2 and LIGHT induce classical and noncanonical NF-kappa B-dependent proinflammatory gene expression in vascular endothelial cells. J Immunol. 2008;180:3467-77.

74. Pablos JL, Santiago B, Galindo M, Torres C, Brehmer MT, Blanco FJ, et al. Synoviocyte-derived CXCL12 is displayed on endothelium and induces angiogenesis in rheumatoid arthritis. J Immunol. 2003;170:2147-52.

75. Noort AR, van Zoest KP, Weijers EM, Koolwijk P, Maracle CX, Novack DV, et al. NF-kappaB-inducing kinase is a key regulator of inflammation-induced and tumour-associated angiogenesis. J Pathol. 2014;234:375-85.

76. Onder L, Danuser R, Scandella E, Firner S, Chai Q, Hehlgans T, et al. Endothelial cell-specific lymphotoxin-beta receptor signaling is critical for lymph node and high endothelial venule formation. J Exp Med. 2013;210:465-73.

77. Stohl W, Merrill JT, McKay JD, Lisse JR, Zhong ZJ, Freimuth WW, et al. Efficacy and safety of belimumab in patients with rheumatoid arthritis: a phase II, randomized, double-blind, placebo-controlled, dose-ranging study. J Rheumatol. 2013:40:579-89.

78. Genovese MC, Fleischmann RM, Greenwald M, Satterwhite J, Veenhuizen M, Xie $L$, et al. Tabalumab, an anti-BAFF monoclonal antibody, in patients with active rheumatoid arthritis with an inadequate response to TNF inhibitors. Ann Rheum Dis. 2012;72:1461-8.

79. Tellander AC, Michaelsson E, Brunmark C, Andersson M. Potent adjuvant effect by anti-CD40 in collagen-induced arthritis. Enhanced disease is accompanied by increased production of collagen type-II reactive IgG2a and IFN-gamma. J Autoimmun. 2000;14:295-302. 
80. Li L, Wang H, Wang B. Anergic cells generated by blocking CD28 and CD40 costimulatory pathways in vitro ameliorate collagen induced arthritis. Cell Immunol. 2008;254:39-45.

81. Durie FH, Fava RA, Foy TM, Aruffo A, Ledbetter JA, Noelle RJ. Prevention of collagen-induced arthritis with an antibody to gp39, the ligand for CD40. Science. 1993:261:1328-30.

82. Yildirim-Toruner C, Diamond B. Current and novel therapeutics in the treatment of systemic lupus erythematosus. J Allergy Clin Immunol. 2011;127:303-12. quiz 313-304.

83. Fava RA, Notidis E, Hunt J, Szanya V, Ratcliffe N, Ngam-Ek A, et al. A role for the lymphotoxin/LIGHT axis in the pathogenesis of murine collagen-induced arthritis. J Immunol. 2003;171:115-26.

84. Genovese MC, Greenwald MW, Alloway JA, Baldassare AR, Chase W, Newman C. Efficacy and safety of baminercept in the treatment of rheumatoid arthritis (RA) results of the phase $2 \mathrm{~B}$ study in the TNF-IR population [abstract]. Arthritis Rheum. 2009;60:417.

85. Emu B, Luca D, Offutt C, Grogan JL, Rojkovich B, Williams MB, et al. Safety, pharmacokinetics, and biologic activity of pateclizumab, a novel monoclonal antibody targeting lymphotoxin alpha: results of a phase I randomized, placebo-controlled trial. Arthritis Res Ther. 2012;14:R6.

86. Kamijo S, Nakajima A, Ikeda K, Aoki K, Ohya K, Akiba H, et al. Amelioration of bone loss in collagen-induced arthritis by neutralizing anti-RANKL monoclonal antibody. Biochem Biophys Res Commun. 2006;347:124-32

87. Cohen SB, Dore RK, Lane NE, Ory PA, Peterfy CG, Sharp JT, et al. Denosumab treatment effects on structural damage, bone mineral density, and bone turnover in rheumatoid arthritis: a twelve-month, multicenter, randomized, double-blind, placebo-controlled, phase II clinical trial. Arthritis Rheum. 2008;58:1299-309.

88. Li K, McGee LR, Fisher B, Sudom A, Liu J, Rubenstein SM, et al. Inhibiting NF-kappaB-inducing kinase (NIK): discovery, structure-based design, synthesis, structure-activity relationship, and co-crystal structures. Bioorg Med Chem Lett. 2013:23:1238-44

89. Pletz N, Schon M, Ziegelbauer K, Emmert S, Liu N, Dobbelstein $M$, et al. Doxorubicin-induced activation of NF-kappaB in melanoma cells is abrogated by inhibition of IKKbeta, but not by a novel IKKalpha inhibitor. Exp Dermatol. 2012;21:301-4

90. Varfolomeev E, Blankenship JW, Wayson SM, Fedorova AV, Kayagaki N, Garg $P$, et al. IAP antagonists induce autoubiquitination of c-IAPs, NF-kappaB activation, and TNFalpha-dependent apoptosis. Cell. 2007;131:669-81.

91. Gray CM, McCorkell KA, Chunduru SK, McKinlay MA, May MJ. Negative feedback regulation of NF-kappaB-inducing kinase is proteasome-dependent but does not require cellular inhibitors of apoptosis. Biochem Biophys Res Commun. 2014;450:341-6.

92. Mak PY, Mak DH, Ruvolo V, Jacamo R, Kornblau SM, Kantarjian H, et al. Apoptosis repressor with caspase recruitment domain modulates second mitochondrial-derived activator of caspases mimetic-induced cell death through BIRC2/MAP3K14 signalling in acute myeloid leukaemia. Br J Haematol. 2014:167:376-84.

93. Condon SM, Mitsuuchi Y, Deng Y, LaPorte MG, Rippin SR, Haimowitz T, et al. Birinapant, a smac-mimetic with improved tolerability for the treatment of solid tumors and hematological malignancies. J Med Chem. 2014;57:3666-77.

94. Sehnert B, Burkhardt H, Wessels JT, Schröder A, May MJ, Vestweber D, et al NF-kappaB inhibitor targeted to activated endothelium demonstrates a critical role of endothelial NF-kappaB in immune-mediated diseases. Proc Natl Acad Sci U S A. 2013:110:16556-61. 